\title{
THE FACTOR STRUCTURE AND RELIABILITY OF A SIX-ITEM SENSE OF COHERENCE MEASURE
}

\author{
Antoni Barnard; Helene Muller; University of South Africa
} Address correspondence to Antoni Barnard, Department of Industrial and Organisational Psychology, PO Box 392 ,
UNISA, Pretoria, 0003, South Africa. Cell: +2782375 2696; Mail: barnaha@unisa.ac.za

The study investigated the factor structure and reliability of a six-item sense of coherence (SOC) measure. Participants were a South African white collar employee sample $(n=7185)$ purposively selected from over 300 different companies across various business sectors. The sample constituted $34 \%$ male and $66 \%$ female and $34 \%$ Black, $18 \%$ Coloured, $11 \%$ Indian and $37 \%$ White employees. Exploratory factor analysis (EFA) was used for the structural analysis. The reliability of the scores was also estimated. A one-dimensional structure seemed to best represent the six-item SOC measure. The internal reliability of the scores from the measure was high.

Keywords: Sense of coherence, orientation to life questionnaire, exploratory factor analysis, employee wellness

Employee wellness is imperative for productive organisational functioning and remains a vital research focus in optimising human talent (Rothmann \& Ekkerd, 2007). Various positive psychology constructs are continuously researched as essential in understanding individual coping behaviour, strengths, a health promoting life orientation and the general wellness of employees. In particular SOC has been widely regarded as a core construct reflecting employee coping and wellness (Eriksson \& Lindström, 2006; Feldt et al., 2011). Measurement issues remain to be resolved and particularly the factor structure and reliability of different SOC measure formats. Whilst the theoretical SOC model is widely accepted as useful in applied psychology, results differ on the structural equivalence of original and adjusted SOC measures with the underlying theoretical SOC construct (Van Schalkwyk \& Rothmann, 2008). Moreover, Togari, Yamazaki, Nakayama and Shimizu (2007) argue that Antonovsky's original SOC-scales, the 29- and 13-item Orientation to Life Questionnaires (OLQ-29 and OLQ-13) are too extensive to be used in large multipurpose population surveys, high- lighting the need for developing shortened versions.

SOC is generally defined as a global life orientation reflecting confidence in one's ability to function meaningfully, with ad- equate resources in a manageable environment. As such SOC is conceptualised as the dynamic interplay between the three subcomponents of comprehensibility, manageability and meaningfulness (Eriksson \& Lindström, 2005; Feldt et al.

2011). Comprehensibility constitutes the cognitive component of SOC through which one regards environmental stimuli to be structured, predictable, clear and explicable. Manageability is the instrumental or behavioural component of SOC and represents one's perception that there are sufficient, useful re- sources available and accessible in one's intrinsic and extrinsic environment to manage any confronting life demands. Lastly, meaningfulness is regarded as the motivational component of SOC denoting the belief that challenges and demands in life are worthy and meaningful to engage with and spend effort in.

The three SOC-subcomponents identified by Antonovsky do not consistently appear in factor analytic research (Feldt et al.2007; Jacobsson, 2011; Naaldenberg, Tobi, Van den Esker, \& Vaandrager, 2011). Some studies establish a one factor structure (Bernabé et al., 2009; Hittner, 2007) and others a three factor structure, yet not necessarily in line with the original conceptualisation of SOC's three subcomponents (Naaldenberg et al., 2011). It seems that when confirmatory factor analysis methods are applied, a theoretically congruent three factor structure does emerge for the OLQ-13 (Feldt et al., 2007; Söderhamn \& Holmgren, 2004). Yet, multi-factorial structures have also been found, including as many as two, three, five, six and 11 factor structures (Eriksson \& Lindström, 2005; Van Schalkwyk \& Rothmann, 2008). With regard to South African research a one dimensional structure mostly seem to explain the SOC construct (Barnard, Peters, \& Muller, 2010; Fourie, Rothmann, \& Van de Vijver 2008; Muller \& Rothmann, 2009; Van Schalkwyk \& Rothmann, 2008). In line with Antonovsky's (1993) warning against the empirical use of OLQ subscales, Muller and Rothmann (2009) do not anticipate SOC subcomponents to function independently because although the three subcomponents are conceptually distinguishable they are interrelated and form part of a unitary SOC construct.

Studies exploring the factorial structure of SOC measures mostly apply exploratory or confirmatory factor analysis. Ac- cording to Naaldenberg et al. (2011), studies applying confirmatory factor analysis present a better fit for models aligning with the three dimensional conceptualisation of the SOC construct. Bernabé et al. (2009) however regard these confirmatory factor analysis results as ambiguous due to model modifications made to achieve acceptable fit to the data. Moreover, due to the un- certainty about the factor structure of the SOC evident from varying construct validity results with the OLQ-13 and the OLQ-29, Jacobsson (2011) recommends the application of exploratory factor analysis as more appropriate in testing the SOC structure. The need for and potential efficiency value of a short SOC measure has been noted in this article (compare Togari et al. 2007). A variety of translated and shortened versions of the SOC have thus been applied worldwide in different populations

(Naaldenberg et al., 2011) yet with varying results as to view SOC as a one or three factor model (Bernabé et al., 2009; Muller \& Rothmann, 2009; Naaldenberg et al., 2011). This study therefore aimed at exploring and confirming the factor structure of a 
six-item Orientation to Life Questionnaire (OLQ-6) and at testing its reliability in a large scale South African employee sample. The results contribute to the current body of research and confirmed a six variable one factor solution for the OLQ-6.

\section{METHOD}

Participants and setting

The sample data $(n=7185)$ were purposively drawn from over 300 companies across various business industries in South Africa, including finance, banking, construction, education, retail, mining, food and beverage, government departments, healthcare, travel and leisure, technology, telecommunications, professional services, chemical, utilities, automotive, real estate and manufacturing to represent white collar, sedentary employees with e-mail access. The demographic characteristics of the sample are depicted in table 1 below.

\section{INSTRUMENTS AND MEASURES}

The six items of the SOC, selected from the original OLQ-29, were items 8 and 28 (meaningfulness), 12 and 19 (Comprehensibility) as well as 9 and 29 (manageability) as identified in the study by Van Schalkwyk and Rothmann (2008). Items are scored on a 7-point ordinal rating scale varying from "very often" (1) to very seldom or never (7) for five of the items and one item's rating scale varying from "no clear goals or purpose at all" (1) to "very clear goals and purpose" (7). Addition- ally, data on the participants' demographics were also considered.

\section{DATA ANALYSIS}

Statistical analysis was performed with the Statistical Analysis System (SAS) software package. The dataset was randomly split into three subsets of $n_{i}=2395$, ( $\left.i=1 . .3\right)$ each retaining a good representation of the same sample-population (see Friendly, 1995). It was hypothesized that if a common factor model of best fit is determined for the first subset that this is the model of best fit for the entire sample $(n=7185)$. The models of best fit for the remaining two subsets were then compared against the hypothesized model to validate the model of best fit for the entire sample

\section{Table 1}

Sample Characteristics

\begin{tabular}{|c|c|c|c|}
\hline & Category & Frequency & Percent \\
\hline Age & $\begin{array}{l}<25 \\
26-35 \\
36-45 \\
46-55 \\
55+ \\
\text { missing = } 3\end{array}$ & $\begin{array}{r}684 \\
3018 \\
1919 \\
1099 \\
462\end{array}$ & $\begin{array}{r}9.52 \\
42.02 \\
26.72 \\
15.30 \\
6.43\end{array}$ \\
\hline Gender & $\begin{array}{l}\text { Male } \\
\text { Female } \\
\text { missing = } 16\end{array}$ & $\begin{array}{l}2433 \\
4726\end{array}$ & $\begin{array}{l}33.94 \\
66.06\end{array}$ \\
\hline Population group & $\begin{array}{l}\text { Black } \\
\text { Coloured } \\
\text { Indian } \\
\text { White } \\
\text { missing = } 7\end{array}$ & $\begin{array}{r}2428 \\
1257 \\
823 \\
2670\end{array}$ & $\begin{array}{l}33.83 \\
17.51 \\
11.47 \\
37.20\end{array}$ \\
\hline Marital status & $\begin{array}{l}\text { Single } \\
\text { Married } \\
\text { Divorced } \\
\text { missing = } 12\end{array}$ & $\begin{array}{r}2625 \\
3823 \\
725\end{array}$ & $\begin{array}{l}36.60 \\
53.30 \\
10.11\end{array}$ \\
\hline Income level & $\begin{array}{l}<R 5000 \\
R 5001-R 10000 \\
R 10001-R 15000 \\
R 15001-R 20000 \\
\text { R20001-R30000 } \\
\text { R30000+ } \\
\text { missing = } 236\end{array}$ & $\begin{array}{r}439 \\
2088 \\
1737 \\
1020 \\
925 \\
740\end{array}$ & $\begin{array}{r}6.32 \\
30.05 \\
25.00 \\
14.68 \\
13.31 \\
10.65\end{array}$ \\
\hline
\end{tabular}



Due to the large data subsets ( $n=2395$ per set) multi-normal approximation could be assumed. Therefore maximum likely hood was applied as it leads to more accurate estimates when applied to larger samples, provides tests regarding the number of common factors underlying a data structure and readily tests for goodness of fit (SAS/STATS, 1999; Friendly, 1995). Oblique rather than orthogonal transformations to enhance the factor pattern of extracted factors through PROMAX rotation (SAS/STATS, 1999). With the Chi-square statistic $\left(x^{2}\right)$ being sensitive to large sample size, further goodness of fit criteria were acquired and included calculation of Bartlett's chi-square test, Kaiser's mea- sure of sampling adequacy, Akaike Information Criterion (AIC), Schwartz's Bayesian Information criterion (BIC) and Tucker Lewis reliability coefficient (TLC). When several factor analytic models are compared, the model with the smallest BIC and AIC indicates the best fit (SAS/STATS, 1999) and TLC values greater than 0.9 indicates a model with good fit (Friendly, 1995). Scale reliability testing was finally conducted on the factor model of best fit calculating Split-half, Cronbach alpha and Spearman Brown internal consistency indexes.

\section{RESULTS}

\section{Structure of the Six-Item SOC}

Results of the factor analysis conducted on the first sample subset's OLQ-6 data applying principal axis and maximum likelihood extraction methods with PROMAX rotation are depicted in table 2. The number of factors to be extracted was deter- mined by the scree-plots' results, Kaiser's eigenvalue criterion (eigenvalues $>1$ ), the proportion of variance (communality $<0.4$ ) accounted for by a factor (Hatcher, 1994) and the various good- ness of fit criteria.

Principal axis analysis results from subset 1 initially show a 1-factor model of best fit with Kaiser's criterion indicating high common variance (MSA > 0.8) and justifying factor analysis of the data. Maximum likelihood with PROMAX rotation further demonstrate the overall and individual variables' Kaiser criterion are all greater than 0.8 , confirming that the data is appropriate for a common factor analysis approach. Good fit statistics were demonstrated for a two-factor maxi- mum likelihood model with Chi-square statistic significant on the $0.1 \%$ level $\left(x^{2}=5638.76\right)$ as the AIC and the BIC reached their smallest value for the two factor model. Similarly the TLC was closest to one for the two factor maximum likelihood model. Analysis of the scree-plot, eigenvalues, communalities and factor patterns however justifies a unifactorial structure above a two-factor structure. The interpretability of the two factors of the 6-variable model were not clearly fitting the theoretical subcomponents of the SOC construct, further favouring a one factor model as presenting the best underlying data structure.

On completion of the analysis of the first data subset it was hypothesized that one factor underlies the response data of a six variable factor analysis model and that this factor reliably measures a combined comprehensibility-manageability- meaningfulness SOC construct. Next this hypothesis was tested with the second and third data subsets applying the same exploratory factor analysis process. Tables 3 and 4 below depict the results of the factor analysis conducted on the second and third sample subset's OLQ-6 data applying principal axis and maximum likelihood extraction methods with PROMAX rotation. By following the same reasoning as followed for the first subset results, it can be deduced that for the six variables, one factor solution are again presented as the model of best fit for both the second and third data subsets. Although the criteria indicated in tables 3 and 4 potentially show that the two factor model might present as the best model (the AIC and the BIC reach their smallest value for the two maximum likelihood factor model and the TLC is closest to 1 for the two factor maximum likelihood model), the differences between the prior and final communalities for each variable in both subsets were again the smallest for the one factor model.

\section{Scale Reliability Testing: Internal Consistency Reliability}

Results (summarized in table 5 below) show that the reliability of the 6 -item scale is higher $(a=0.86)$ than for 3 -item scales ( $a=$ $0.68,0.74,0.74$ and 0.85 for 4 different 3 -item permutations of the questionnaire).

\section{CONCLUSION}

This study contributes significantly to the body of SOC re- search in confirming the efficiency value of a short version SOC measure for more efficient use in online applications and in large scale employee surveys. Results support the notion that SOCscale versions shorter than 12 items do not provide adequate scope to measure three related but distinct factors (compare Bernabé et al., 2009 and Togari et al., 2007). 
Table 2

Summary of FA Models Evaluated for Goodness of Fit for Subset1 (As Determined With SAS Version 9.2)

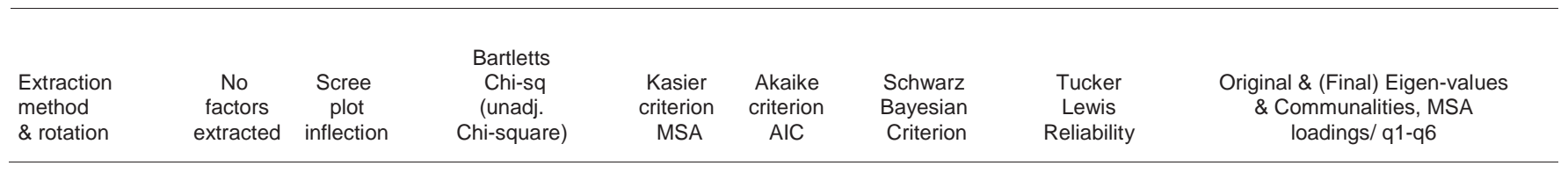

Subset 1 ( 6 variables, q1-q6)

(Kaiser's MSA per variable: 0.930 .900 .870 .880 .860 .85 )

\begin{tabular}{|c|c|c|c|c|c|c|c|c|}
\hline \multirow[t]{3}{*}{ ML, promax } & 1 & 1 & $\begin{array}{l}5638.76^{\star \star \star} \\
(192.25)\end{array}$ & 0.8770 & 174.25 & 123.31 & 0.9458 & $\begin{array}{l}\text { v1 v2 v3 v4 v5 v6 } \\
\text { Prelim \& Final eigenvalues } \\
6.400 .18-0.27-0.13-0.25-0.34 \\
7.670 .330 .05-0.02-0.11-0.25 \\
\text { Communalities Prior \& Final } \\
0.330 .310 .510 .550 .550 .59 \\
0.380 .320 .550 .630 .610 .67 \\
\text { Factor pattern for I factor } \\
82 \quad 79 \quad 78 \quad 74 \quad 62 \quad 57\end{array}$ \\
\hline & 2 & 1 & $\begin{array}{c}5638.76^{\star \star *} \\
(23.28)\end{array}$ & 0.8770 & 15.29 & -7.35 & 0.987 & $\begin{array}{llllll}\text { v1 v2 v3 v4 v5 v6 } & \text { val } \\
\text { Prelim } \& \text { Final eigenvalues } \\
6.41 & 0.18 & -0.03 & -0.13 & -0.25 & -0.34 \\
1.89 & 1.33 & 0.09 & 0.04 & -0.04 & -0.10 \\
\text { Communalities Prior } \& \text { Final } \\
0.33 & 0.31 & 0.51 & 0.55 & 0.55 & 0.59 \\
0.37 & 0.33 & 0.83 & 0.61 & 0.67 & 0.71 \\
\text { Factor pattern for } & 2 \text { factors } \\
80 & 76 & 52 & 45 & 06 & 24 \\
04 & 12 & 33 & 21 & 88 & 40\end{array}$ \\
\hline & 3 & 1 & \multicolumn{6}{|c|}{ minimum eigen value criterion not satisfied; no solution for number of factors to extract } \\
\hline PA, promax & 1 & 1 & -0.8770 & - & - & - & & $\begin{array}{l}\text { v1 v2 v3 v4 v5 v6 } \\
\text { Prelim eigenvalues } \\
3.110 .10-0.02-0.07-0.11-0.17 \\
\text { Communalities Prior } \\
0.340 .310 .510 .540 .550 .59 \\
\text { Factor pattern for I factor } \\
8078 \quad 77 \quad 75 \quad 61 \quad 57\end{array}$ \\
\hline
\end{tabular}

Subset 1 ( 5 variables, q1, q3-q6)

(Kaiser's MSA per variable: $\left.\begin{array}{lllll}0.93 & 0.87 & 0.86 & 0.84 & 0.83\end{array}\right)$

\begin{tabular}{|c|c|c|c|c|c|c|c|}
\hline \multirow[t]{2}{*}{ ML, promax } & 1 & $\begin{array}{r}4845.69 \\
(96.31)\end{array}$ & 0.8587 & 86.31 & 58.01 & 0.96 & $\begin{array}{lllll}v 1 & v 3 & v 4 & v 5 & v 6 \\
\text { Prelim } \& \text { Final eigenvalues } \\
5.78 & 0.04 & -0.09 & -0.26 & -0.31 \\
7.29 & 0.25 & -0.00 & -0.09 & -0.15 \\
\text { Communalities } & \text { Prior } \& \text { Final } \\
0.34 & 0.47 & 0.54 & 0.54 & 0.59 \\
0.38 & 0.52 & 0.63 & 0.62 & 0.70 \\
\text { Factor pattern for I factor } \\
83 \quad 79 & 79 & 72 & 62\end{array}$ \\
\hline & 2 & $\begin{array}{r}4845.69 \\
(0.30)\end{array}$ & 0.8586 & -1.70 & -7.36 & 1.00 & \begin{tabular}{llllll}
$v 1$ & $v 3$ & $v 4$ & $v 5$ & $v 6$ \\
Prelim & \& Final eigenvalues \\
5.78 & 0.04 & -0.09 & -0.26 & -0.31 \\
8.34 & 0.51 & 0.01 & 0.00 & -0.01 \\
\multicolumn{4}{c}{ Communalities Prior \& } & Final \\
0.34 & 0.47 & 0.54 & 0.54 & 0.59 \\
0.38 & 0.64 & 0.64 & 0.69 & 0.71 \\
& \\
Factor pattern for 2 factors \\
78 & 67 & 07 & 32 & 31 \\
07 & 22 & 75 & 54 & 35
\end{tabular} \\
\hline
\end{tabular}

Note. ML: Maximum Likelihood; PA: Principal axis; Promax: Oblique rotation; MSA: Kaiser's measure of sampling adequacy; *** Highly significant at the $0.1 \%$ level 
Table 3

Summary of FA Models Evaluated for Goodness of Fit for Subset1 (As Determined With SAS Version 9.2)

\begin{tabular}{|c|c|c|c|c|c|c|c|c|}
\hline $\begin{array}{l}\text { Extraction } \\
\text { method } \\
\text { \& rotation }\end{array}$ & $\begin{array}{c}\text { No } \\
\text { factors } \\
\text { extracted }\end{array}$ & $\begin{array}{l}\text { Scree } \\
\text { plot } \\
\text { inflection }\end{array}$ & $\begin{array}{c}\text { Bartletts } \\
\text { Chi-sq } \\
\text { (unadj. } \\
\text { Chi-square) }\end{array}$ & $\begin{array}{l}\text { Kasier } \\
\text { criterion } \\
\text { MSA }\end{array}$ & $\begin{array}{l}\text { Akaike } \\
\text { criterion } \\
\text { AIC }\end{array}$ & $\begin{array}{l}\text { Schwarz } \\
\text { Bayesian } \\
\text { Criterion }\end{array}$ & $\begin{array}{l}\text { Tucker } \\
\text { Lewis } \\
\text { Reliability }\end{array}$ & $\begin{array}{c}\text { Original \& (Final) Eigen-values } \\
\text { \& Communalities, MSA } \\
\text { loadings/ q1-q6 }\end{array}$ \\
\hline \multicolumn{9}{|c|}{$\begin{array}{l}\text { Subset } 2 \\
\text { [Kaiser's MSA per variable: } 0.930 .910 .870 .860 .850 .86 \text { ] }\end{array}$} \\
\hline \multirow[t]{3}{*}{ ML, Promax } & 1 & 1 & $\begin{array}{l}5226.80^{* * *} \\
(162.10)\end{array}$ & 0.8731 & 144.10 & 93.15 & 0.951 & $\begin{array}{l}\text { v1 v2 v3 v4 v5 v6 } \\
\text { Prelim \& Final eigenvalues } \\
5.910 .16-0.05-0.12-0.24-0.33 \\
7.140 .310 .03-0.02-0.10-0.22 \\
\text { Communalities Prior \& Final } \\
0.300 .260 .500 .560 .530 .54 \\
0.340 .280 .550 .660 .600 .61 \\
\text { Factor pattern for I factor } \\
8178 \quad 77 \quad 74 \quad 58 \quad 53\end{array}$ \\
\hline & 2 & 1 & $\begin{array}{r}5226.80^{* * *} \\
(9.239)\end{array}$ & 0.8731 & 1.24 & -21.41 & 0.996 & 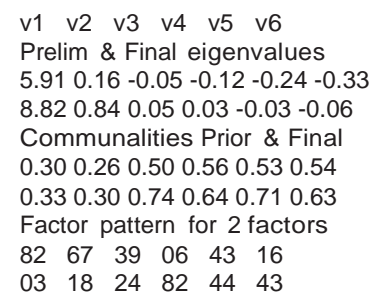 \\
\hline & 3 & \multicolumn{6}{|c|}{ minimum eigen value criterium overrules number factors to extract specification } & \\
\hline PA, Promax & 1 & 1 & -0.8731 & - & - & - & & $\begin{array}{l}\text { v1 v2 v3 v4 v5 v6 } \\
\text { Prelim eigennvalues } \\
2.980 .09-0.03-0.07-0.11-0.16 \\
\text { Communalities Prior } \\
0.300 .260 .500 .560 .530 .54 \\
\text { Factor pattern for I factor } \\
80 \quad 77 \quad 7674 \quad 58 \quad 54\end{array}$ \\
\hline
\end{tabular}

Subset 2 ( 5 variables, q1, q3-q6)

(Kaiser's MSA per variable: $\left.\begin{array}{lllll}0.92 & 0.86 & 0.84 & 0.84 & 0.84\end{array}\right)$

\begin{tabular}{|c|c|c|c|c|c|c|c|c|}
\hline \multirow[t]{2}{*}{ ML, promax } & 1 & 1 & $\begin{array}{l}4580.03^{\star \star *} \\
(106.24)\end{array}$ & 0.8515 & 96.24 & 67.92 & 0.956 & 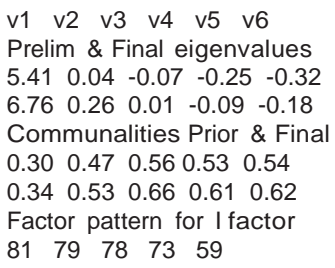 \\
\hline & 2 & 1 & $\begin{array}{r}4580.03^{* * *} \\
(0.0759)\end{array}$ & 0.8515 & -1.924 & -7.587 & 1.00 & 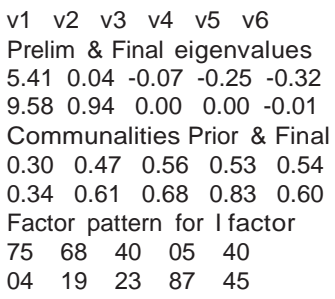 \\
\hline
\end{tabular}

Note. ML: Maximum Likelihood; PA: Principal axis; Promax: Oblique rotation; MSA: Kaiser's measure of sampling adequacy; highly significant at the $0.1 \%$ level 

Table 4

Summary of FA Models Evaluated for Goodness of Fit for Subset1 (As Determined With SAS Version 9.2)

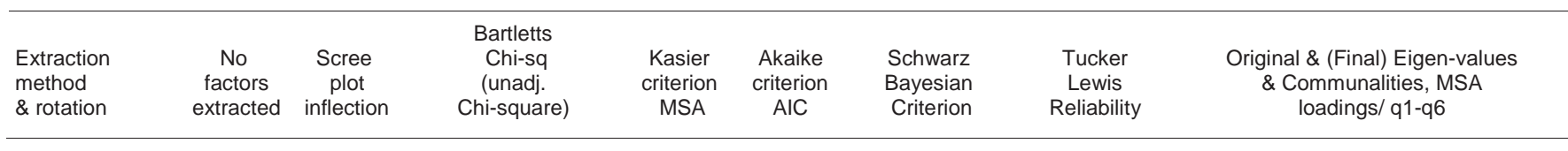

Subset 3

(Kaiser's MSA per variable: 0.930 .920 .870 .870 .860 .87 )

\begin{tabular}{|c|c|c|c|c|c|c|c|c|}
\hline ML, Promax & 1 & 1 & $\begin{array}{l}5578.33^{* * *} \\
(157.25)\end{array}$ & 0.8779 & 139.24 & 88.31 & 0.956 & $\begin{array}{l}\text { v1 v2 v3 v4 v5 v6 } \\
\text { Prelim \& Final eigenvalues } \\
6.400 .15-0.05-0.11-0.23-0.34 \\
7.760 .300 .04-0.01-0.09-0.23 \\
\text { Communalities Prior \& Final } \\
0.310 .280 .510 .580 .570 .56 \\
0.340 .300 .550 .670 .640 .64 \\
\text { Factor pattern for I factor } \\
828080 \quad 74 \quad 5955\end{array}$ \\
\hline & 2 & & $\begin{array}{c}5578.33^{* \star *} \\
(5.82)\end{array}$ & 0.8779 & -2.18 & -24.82 & 0.998 & 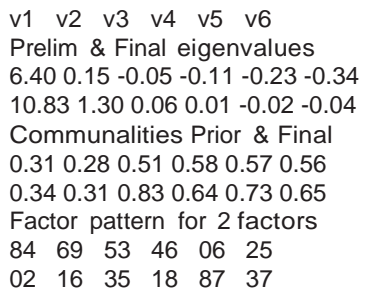 \\
\hline PAF & 1 & & - & 0.8779 & - & - & - & $\begin{array}{l}\text { v1 v2 v3 v4 v5 v6 } \\
\text { Prelim eigenvalues } \\
3.080 .08-0.03-0.06-0.11-0.16 \\
\text { Communalities Prior \& Final } \\
0.310 .280 .510 .580 .570 .55 \\
\text { Factor pattern for I factor } \\
807978 \quad 755855\end{array}$ \\
\hline
\end{tabular}

Subset 3 ( 5 variables, q1, q3-q6)

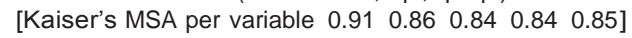

\begin{tabular}{|c|c|c|c|c|c|c|c|}
\hline \multirow[t]{2}{*}{ ML, promax } & 1 & $\begin{array}{l}4873.37^{* \star *} \\
(104.65)\end{array}$ & 0.855 & 94.65 & 66.35 & 0.959 & $\begin{array}{llllll}v 1 & v 3 & v 4 & \text { v5 } & \text { v6 } \\
\text { Prelim } & \& & \text { Final } & \text { eigenvalues } \\
5.85 & 0.03 & -0.06 & -0.24 & -0.34 \\
7.36 & 0.23 & 0.03 & -0.05 & -0.21 \\
\text { Communalities } & \text { Prior } \& \text { Final } \\
0.31 & 0.48 & 0.57 & 0.56 & 0.55 \\
0.35 & 0.53 & 0.67 & 0.65 & 0.65 \\
\text { Factor pattern for } 1 \text { factor } \\
82 & 81 & 80 & 73 & 59\end{array}$ \\
\hline & 2 & $\begin{array}{c}4873.37^{* \star *} \\
()\end{array}$ & & $\mathrm{MSA}=0.855$ & rocess c & converge & $\begin{array}{l}\text { v1 v3 v4 v5 v6 } \\
\text { Prelim \& Final eigenvalues } \\
5.85 \quad 0.03 \quad-0.06-0.24 \quad-0.34 \\
\text { Communalities Prior \& Final } \\
0.310 .48 \quad 0.570 .56 \quad 0.55 \\
\text { Factor pattern for } 2 \text { factors }\end{array}$ \\
\hline
\end{tabular}

Note. ML: Maximum Likelihood; PA: Principal axis; Promax: Oblique rotation; MSA: Kaiser's measure of sampling adequacy; ${ }^{\star \star \star}$ Highly significant at the $0.1 \%$ level 
Table 5

Scale Reliability Testing Results (Calculated with SAS Version 9.2 and SPSS Version 20)

\begin{tabular}{|c|c|c|c|}
\hline Reliability coefficients & $\begin{array}{l}\text { ty coefficier } \\
\text { subset } 1\end{array}$ & $\begin{array}{l}\text { on which c } \\
\text { subset } 2\end{array}$ & $\begin{array}{l}\text { ts were calculated } \\
\text { q1-q6 }\end{array}$ \\
\hline \multicolumn{4}{|c|}{ Subset 1 (q1 q3 q5) and subset 2 (q2 q4 q6) SAS version 9.2} \\
\hline Half split (q1, q31, q5 vs q2 q4 q6) & q1 q3 q5 & q2 q4 q6 & $q 1-q 6$ \\
\hline Cronbach alpha & 0.740 & 0.744 & 0.861 \\
\hline Correlation between two halves of scale & \multirow{2}{*}{\multicolumn{2}{|c|}{0.790}} & \\
\hline Spearman Brown & & & 0.883 \\
\hline \multicolumn{4}{|c|}{ Subset $1(q 1-q 3)$ and subset 2 (q4-q6) SPSS version $20 . N=7185$, missing=818 } \\
\hline Half split (q1, q31, q5 vs q2 q4 q6) & q1-q3 & q4-q6 & \\
\hline Cronbach alpha & 0.680 & 0.845 & 0.861 \\
\hline Correlation between two halves of scale & \multicolumn{2}{|c|}{0.719} & \\
\hline Spearman Brown & & & 0.837 \\
\hline Guttman split half coeff (lambda 4) & & & 0.829 \\
\hline
\end{tabular}




\section{REFERENCES}

Antonovsky, A. (1979). Health, stress and coping. San Fran- cisco, CA: Jossey-Bass.

Antonovsky, A. (1993). The structure and properties of the sense of coherence scale. Journal of Science and Medicine, 36, 725-733.

Barnard, H. A., Peters, D., \& Muller, H. (2010). Financial health and sense of coherence. SA Journal of Human Resource Management, 8(1), 1-12.

Bernabé, E., Tsakos, G., Watt, R. G., Suominen-Taipale, A. L., Uutela, A., Vahtera, J., \& Kivimäki, M. (2009). Structure of the sense of coherence scale in a nationally representative sample. The Finnish Health 2000 survey. Quality of Life Research, 18(5), 629-636.

Eriksson, M., \& Lindström, B. (2005). Validity of Antonovsky's sense of coherence scale: A systematic review. Journal of Epidemiology and Community Health, 59(6), 460-466.

Eriksson, M., \& Lindström, B. (2006). Antonovsky's sense of coherence scale and the relation with health: A systematic review. Journal of Epidemiology and Community Health, 60(5), 376-381.

Feldt, T., Leskinen, E., Koskenvuo, M., Suominen, S., Vahtera, J., \& Kivimäki, M. (2011). Development of sense of coherence in adulthood: A person-centred approach. The population-based HeSSup cohort study. Quality of Life Research, $20,69-79$.

Feldt, T., Lintula, H., Suominen, S., Koskenvuo, M., Vahtera, J., \& Kivimäki, M. (2007). Structural validity and temporal stability of the 13-item sense of coherence scale: Prospective evidence from the population-based HeSSup study. Quality of Life Research, 16(3), 483-493.

Fourie, L., Rothmann, S., \& Van de Vijver, A. J. R. (2008). A model of work wellness for non-professional counsellors in South Africa. Stress and Health, 24(1), 35-47.

Friendly, M. (1995). Planning a factor analytic study. University of York, UK. Retrieved from http://www.psych.yorku. ca/lab/ psy6140/fa/facplan.htm.

Hatcher, L. (1994). A step by step approach to using the SAS system for factor analysis and structural equation modeling. Cary, North Carolina: SAS Institute.

Hittner, J. B. (2007). Factorial invariance of the 13-item sense of coherence scale across gender. Journal of Health Psychology, 12, 273-280.

Jakobsson, U. (2011). Testing construct validity of the 13-item sense of coherence scale in a sample of older people. The Open Geriatric Medicine Journal, 4, 6-13.

Muller, Y., \& Rothmann, S. (2009). Sense of coherence and employees' perceptions of helping and restraining factors in an organisation. South African Journal for Industrial Psychology, 35(1), 89-98. doi: 10.4102/sajip.v.35i1.731.

Naaldenberg, J., Tobi, H., Van den Esker, F., \& Vaandrager, L. (2011). Psychometric properties of the OLQ-13 scale to measure sense of coherence in a community-dwelling older population. Health and Quality of Life Outcomes, 9(37), 1-9. doi: 10.1186/1477-7525-9-37.

Rothmann, S., \& Ekkerd, J. (2007).The validation of the perceived wellness survey in the South African police service. South African Journal for Industrial Psychology, 33(3), 35-42.

SAS/STATS. 1999. SAS/STAT Version 8 Procedure Guide. Cary, North Carolina: SAS Institute.

Söderhamn, O., \& Holmgren, L. (2004). Testing Antonovsky's sense of coherence (SOC) scale among Swedish physically active older people. Scandanawian Journal of Psychology, 45, 215-221.

Togari, T., Yamazaki, Y., Nakayama, K., \& Shimizu, J. (2007). Development of a short version of the sense of coherence scale for population survey. Journal of Epidemiology and Community Health, 61(10), pp.921-922. 
Van Schalkwyk, L., \& Rothmann, S. (2008). Validation of the orientation to life questionnaire (OLQ) in a chemical factory. South African Journal for Industrial Psychology, 34(2), 31-39.

Volanen, S., Lahelma, E., Silventoinen, K., \& Suominen, S. (2004). Factors contributing to the sense of coherence among men and women. European Journal of Public Health, 14(3), 322-330.

\section{Author Notes}

The authors would like to thank Summit Financial Partners SA for their support in making the data available for research purposes and sponsoring the wellness study through which the data originated. Summit is an independent financial wellbeing consultancy focussing on improving people's quality of life through financial consulting, training and coaching. 